\title{
Critical slowing in a Hodgkin-Huxley neuron near spiking threshold
}

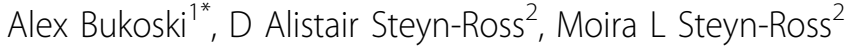 \\ From Twenty First Annual Computational Neuroscience Meeting: CNS*2012 \\ Decatur, GA, USA. 21-26 July 2012
}

As noted by Freeman [1], a quiescent neuron approaching spiking threshold exhibits a nonlinearly increasing sensitivity to stimulus. This growth of subthreshold susceptibility can be quantified by applying a linear multivariate Ornstein-Uhlenbeck analysis to the neuron equations, and this has been verified recently [2] for a reduced two-variable spiking model due to Wilson [3].
Here we generalize this stochastic analysis to the classical four-variable conductance-based Hodgkin-Huxley neuron with type-I excitability [4], perturbed by independent white noises entering the drive current and gating variables. We demonstrate critical slowing downgrowth in amplitude simultaneous with decay in frequency of soma voltage fluctuations-as the neuron

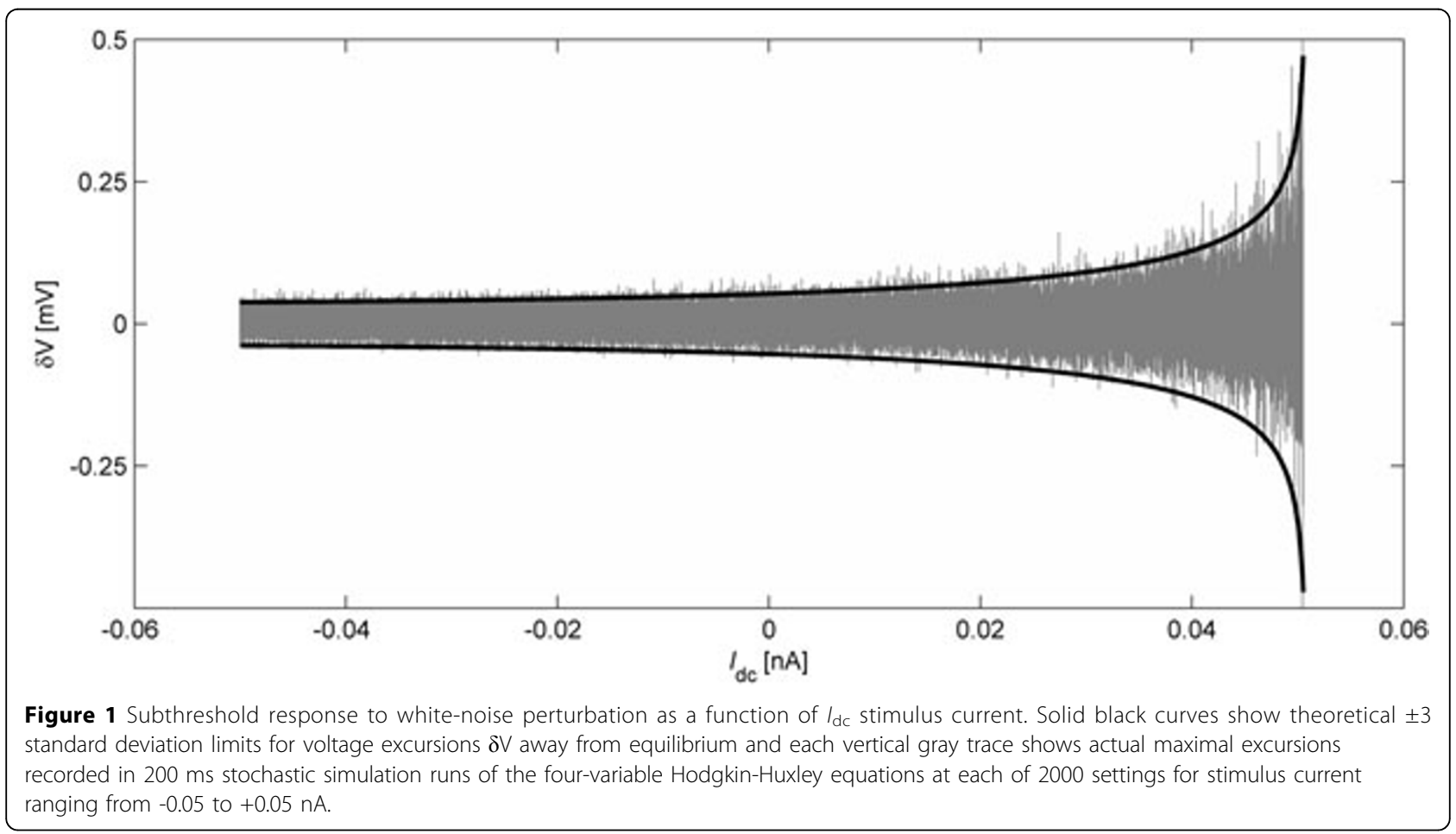

\footnotetext{
* Correspondence: bukoskia@missouri.edu

${ }^{1}$ College of Veterinary Medicine, University of Missouri, Columbia, MO 65203,

USA

Full list of author information is available at the end of the article
}

(c) 2012 Bukoski et al; licensee BioMed Central Ltd. This is an Open Access article distributed under the terms of the Creative Commons 
approaches firing threshold. We show that this behavior is a direct result of the interaction between the model's eigenvalue structure and the noisy environment in which a biological neuron is presumed to function. Stochastic calculus results applied to this four-variable system predict fractional power-law scaling in the divergences for both voltage fluctuations (see Fig. 1) and correlation time as the critical point of saddle-node annihilation is closely approached. Such divergences are expected to be universal characteristics for all type-I neuron models. If these critical fluctuations are communicated to neighboring neurons via ubiquitous electrical gap junctions, then subthreshold neuronal dynamics may play an important role in overall cortical dynamics.

\section{Author details}

${ }^{1}$ College of Veterinary Medicine, University of Missouri, Columbia, MO 65203, USA. ${ }^{2}$ School of Engineering, University of Waikato, Hamilton 3240, New

Zealand.

Published: 16 July 2012

\section{References}

1. Freeman WJ: Neurodynamics, volume transmission, and self-organization in brain dynamics. J Integ Neurosci 2005, 4(4):407-421.

2. Steyn-Ross DA, Steyn-Ross ML, Wilson MT, Sleigh JW: White-noise susceptibility and critical slowing in neurons near spiking threshold. Phys Rev E 2006, 74:051920.

3. Wilson HR: Spikes, Decisions, and Actions: The Dynamical Foundations of Neuroscience. New York: Oxford University Press; 1999.

4. Nowotny T, Rabinovich Ml: Dynamical origin of independent spiking and bursting activity in neural microcircuits. Phys Rev Lett 2007, 98:128106.

doi:10.1186/1471-2202-13-S1-P34

Cite this article as: Bukoski et al:: Critical slowing in a Hodgkin-Huxley neuron near spiking threshold. BMC Neuroscience 2012 13(Suppl 1):P34.

\section{Submit your next manuscript to BioMed Central} and take full advantage of:

- Convenient online submission

- Thorough peer review

- No space constraints or color figure charges

- Immediate publication on acceptance

- Inclusion in PubMed, CAS, Scopus and Google Scholar

- Research which is freely available for redistribution

Submit your manuscript at www.biomedcentral.com/submit
C Biomed Central 